\title{
Biased Agonism in Drug Discovery-Is It Too Soon to Choose a Path?
}

\author{
Martin C. Michel and Steven J. Charlton \\ Department of Pharmacology, Johannes Gutenberg University, Mainz, Germany (M.C.M.); Department of Life Sciences, \\ University of Nottingham, Nottingham, United Kingdom (S.J.C.); and Excellerate Biosciences Ltd., MediCity, Nottingham, United \\ Kingdom (S.J.C.)
}

Received October 20, 2017; accepted January 1, 2018

\section{ABSTRACT}

A single receptor can activate multiple signaling pathways that have distinct or even opposite effects on cell function. Biased agonists stabilize receptor conformations preferentially stimulating one of these pathways, and therefore allow a more targeted modulation of cell function and treatment of disease. Dedicated development of biased agonists has led to promising drug candidates in clinical development, such as the G proteinbiased $\mu$ opioid receptor agonist oliceridine. However, leveraging the theoretical potential of biased agonism for drug discovery faces several challenges. Some of these challenges are technical, such as techniques for quantitative analysis of bias and development of suitable screening assays; others are more fundamental, such as the need to robustly identify in a very early phase which cell type harbors the cellular target of the drug candidate, which signaling pathway leads to the desired therapeutic effect, and how these pathways may be modulated in the disease to be treated. We conclude that biased agonism has potential mainly in the treatment of conditions with a wellunderstood pathophysiology; in contrast, it may increase effort and commercial risk under circumstances where the pathophysiology has been less well defined, as is the case with many highly innovative treatments.

\section{Introduction}

It has been assumed historically that a given $\mathrm{G}$ proteincoupled receptor (GPCR) primarily couples to one $\mathrm{G}$ protein and signaling pathway-for instance, angiotensin II type 1 receptors (AT1Rs), muscarinic $\mathrm{M}_{3}$ receptors, and $\alpha_{1}$-adrenoceptors receptors couple to $G_{q}$; muscarinic $M_{2}$ receptors, $\mu$ opioid receptors and $\alpha_{2}$-adrenoceptors couple to $\mathrm{G}_{\mathrm{i}}$; and $\beta$-adrenoceptors couple to $\mathrm{G}_{\mathrm{s}}$ (Bylund et al., 1994; Dhawan et al., 1996; Caulfield and Birdsall, 1998; de Gasparo et al., 2000). While exceptions to this rule were reported not too long after the definition and classification of $\mathrm{G}$ proteins, it has only become accepted in the past decade that coupling of a single GPCR to multiple $G$ proteins is the rule and not the exception. Receptors typically coupling to $G_{q}$ proteins can also couple to $\mathrm{G}_{\mathrm{i}}$ proteins, for instance, AT1R (Crawford et al., 1992), or to

M.C.M. is a former employee of Boehringer Ingelheim. He also has received consultancy honoraria from Dr. Wilmar Schwabe and Velicept Therapeutics, and is a shareholder of the latter company. S.J.C. is a founding Director and Chief Scientific Officer of Excellerate Bioscience, and a former employee of Novartis.

The work in the laboratory of M.C.M. has been or presently is supported by the Deutsche Forschungsgemeinschaft (Mi 294/8-1) and Velicept Therapeutics. https://doi.org/10.1124/mol.117.110890.
$\mathrm{G}_{\mathrm{s}}$ proteins, for instance, $\alpha_{1 \mathrm{~B}}$-adrenoceptors (Horie et al., 1995). Conversely, typically $\mathrm{G}_{\mathrm{i}}$-coupled receptors such as $\mathrm{M}_{2}$ muscarinic acetylcholine receptors can also couple to $\mathrm{G}_{\mathrm{q}}$ (Schmidt et al., 1995), and typically $\mathrm{G}_{\mathrm{s}}$-coupled receptors such as $\beta_{2^{-}}$and $\beta_{3}$-adrenoceptors can also couple to $\mathrm{G}_{\mathrm{i}}$ (Cao et al., 2000 ) and/or $G_{q}$ (Wenzel-Seifert and Seifert, 2000). Moreover, GPCRs can directly couple not only to G proteins but also to other signaling molecules such as arrestins (Peterson and Luttrell, 2017) or src (Cao et al., 2000). Apparently, the classic or canonical signaling pathway of a receptor is present in most if not all cell types, whereas the additional or noncanonical signaling pathways can exhibit a more restricted presence. For instance, we have detected coupling to cAMP formation upon $\beta$-adrenoceptor stimulation, presumably via $\mathrm{G}_{\mathrm{s}}$, in every cell type we ever studied; in contrast, we only detected coupling to phosphorylation of extracellular signal-regulated kinase (ERK) via $G_{i}$ in only some cell types. This does not necessarily mean that coupling to additional signaling pathways per se is restricted, but it may be too weak in many cell types to be quantified in a robust manner.

The term biased agonism, originally introduced by Jarpe et al. (1998), describes the phenomenon that a ligand preferentially activates one of several signaling pathways, whereas

ABBREVIATIONS: AT1R, angiotensin II type 1 receptor; ERK, extracellular signal-regulated kinase; GPCR, G protein-coupled receptor; JNJ7777120, 1-[(5-chloro-1H-indol-2-yl)carbonyl]-4-methylpiperazine; OAB, overactive bladder; PTX, pertussis toxin; TPP, target product profile; TRV 027, N-methylglycyl-L-arginyl-L-valyl-L-tyrosyl-L-isoleucyl-L-histidyl-L-prolyl-D-alanine. 
another agonist in the same system and acting on the same receptor preferentially activates another pathway (Patel et al., 2010). This phenomenon has also been referred to as stimulus trafficking (Kenakin, 1995), functional dissociation (Whistler et al., 1999), biased inhibition (Kudlacek et al., 2002), differential engagement (Manning, 2002), and liganddirected signaling (Michel and Alewijnse, 2007). Such preferential coupling translates into differential induction of receptor trafficking and gene transcription programs (Maudsley et al., 2015; Delgado-Peraza et al., 2016). Of note, the concept of biased agonism is not necessarily restricted to GPCRs and could also be applied to other signaling processes where the ligandactivated molecule may bind to more than one other partner, for instance, to steroid hormone receptors and other ligand-activated transcription factors (Michel et al., 2014).

Perhaps the best-known hypothesis for the molecular basis of biased agonism relates to the fact that each ligand stabilizes a specific conformation of a receptor (Kenakin and Morgan, 1989; Kenakin and Miller, 2010; Costa-Neto et al., 2016). This has been demonstrated using a variety of techniques, from NMR and double electron-electron resonance spectroscopy (Manglik et al., 2015) to stabilization of discrete conformations using allosteric nanobodies (Staus et al., 2016). Since different receptor conformations are likely to exhibit different affinities for various $G$ proteins or $G$ protein versus arrestin, it appears logical that ligands inducing different receptor conformations will also differentially affect coupling to specific $\mathrm{G}$ proteins, i.e., can exhibit biased agonism. Even minor chemical differences between ligands, e.g., their stereoisomers, may lead to preferential activation of distinct signaling pathways of the same receptor (Seifert and Dove, 2009). A structural basis for this is that distinct amino acids within a receptor are critical for coupling to $\mathrm{G}_{\mathrm{s}}$ compared with $\mathrm{G}_{\mathrm{i}}$ proteins (Manglik et al., 2015).

Many cases of proposed biased agonism include receptor binding to arrestins (Peterson and Luttrell, 2017), which in turn is often linked to activation of ERK (Patel et al., 2010; Szakadáti et al., 2015; Delgado-Peraza et al., 2016). Activation of ERK can also occur independently of arrestin, for instance, via src (Cao et al., 2000). Moreover, it has been proposed that receptors primarily coupling to $G_{q}$ or $G_{s}$ proteins may activate ERK via $G_{i}$. An example of the latter are $\beta_{3}$-adrenoceptors, which typically couple to $\mathrm{G}_{\mathrm{s}}$ followed by activation of adenylyl cyclase and generation of cAMP; however, in some cell types they can also cause (moderate) induction of ERK phosphorylation, which is proposed to involve activation of a pertussis toxin (PTX)-sensitive G protein, presumably $\mathrm{G}_{\mathrm{i}}$ (Gerhardt et al., 1999; Soeder et al., 1999). However, the latter finding may not be robust since it is based on the observation that less ERK phosphorylation was observed following pretreatment with PTX, but the effects of PTX on basal ERK phosphorylation had not been assessed. Recent observations from our group confirm that PTX reduces ERK phosphorylation responses but also markedly lowers basal ERK phosphorylation; relative to this lowered basal value, $\beta_{3}$-adrenoceptor ligands, if anything, yielded a greater relative enhancement of ERK phosphorylation than in the absence of PTX (Okeke et al., 2018). Since this may also apply to other receptors, the true role of $G_{i}$ proteins in ERK activation as an alternative signaling pathway remains to be determined. Of note, ERK activation by $\mathrm{G}_{\mathrm{q}}$ - or $\mathrm{G}_{\mathrm{s}}$-coupled receptors may result from activation of these $G$ proteins (Lefkowitz et al., 2002).
Based on the molecular basis of biased agonism, the specific signaling pathway activated by a ligand depends on several factors (Kenakin and Christopoulos, 2013). First, the bimolecular interaction between ligand and receptor favors a specific receptor conformation. This conformation in turn will favor binding to a given $\mathrm{G}$ protein, arrestin, or other signaling molecule. These two properties together define ligand bias (Kenakin, 2015a). Second, the stochiometric ratio of G proteins, arrestins, and other signaling partners affects the degree to which they will be activated by a given receptor conformation (Onfroy et al., 2017). Thus, high expression of one signaling partner may lead to preferential activation of this pathway even if the receptor conformation has somewhat lower affinity for it. These stochiometric ratios define system bias (Kenakin, 2015a). Third, stochiometric ratios of $\mathrm{G}$ proteins and arrestins in a given cell type or tissue can be modified by various physiologic, pathologic, or iatrogenic factors. These effects define dynamic bias (Michel et al., 2014). Fourth, whether a given signaling pathway is stimulated by a ligand may be dominated by the intrinsic efficacy of that ligand for the pathway to be activated, which in turn depends on the relative affinity of the effector molecules for the receptor (Kenakin, 2015b). Of note, ligands may be weak partial agonists or even inverse agonists for one signaling pathway but strong agonists for another signaling pathway, for instance, carvedilol at $\beta_{2}$-adrenoceptors (Wisler et al., 2007 ) or L 748,337 at $\beta_{3}$-adrenoceptors (Sato et al., 2008).

\section{The Promise of Biased Agonism}

Since different $G$ proteins and arrestins can modulate different signaling pathways, which in some cases may even have opposite effects on cell function, it is obvious that a ligand exhibiting biased agonism may yield distinct cellular responses compared with a reference agonist. Some of these signaling responses may be desirable, whereas others are undesirable depending on the clinical condition under consideration. Thus, biased agonism in principle offers the possibility to selectively modulate one cellular/tissue response activated by a given receptor. For obvious reasons, this potential new avenue for selective modulation of cell and tissue function has generated considerable excitement.

The most informative example, and perhaps up to now the only example, of how the potential of biased agonism can be leveraged for the development of novel therapeutics is the discovery of opioid receptor agonists that exhibit analgesic effects but are associated with little constipation and/or respiratory suppression. Initial work had demonstrated that $\beta$-arrestin 2 knockout mice or mice and rats injected with $\beta$-arrestin 2 interfering RNAs exhibited enhanced analgesia in response to opioid receptor agonists but less tolerance development and little constipation or respiratory suppression (Raehal et al., 2011; Kelly, 2013). This suggested that $\mu$ opioid receptor agonists biased for $G$ protein activation, but having little arrestin-mediated effects, may exhibit a beneficial profile in the treatment of pain. Based on such findings, a team at Trevena has developed oliceridine (formerly known as TRV 130), a $\mu$ opioid receptor agonist (DeWire et al., 2013). Oliceridine exhibited robust $G$ protein activation with a potency and efficacy similar to that of morphine, but caused far less arrestin recruitment and receptor internalization. It was a potent analgesic in mice and rats but caused less 
gastrointestinal dysfunction and respiratory suppression than morphine at equally analgesic doses. A clinical phase II study confirmed that oliceridine is a potent analgesic drug in patients (Viscusi et al., 2016), and the Food and Drug Administration has granted breakthrough therapy status to this drug. Oliceridine produced similar analgesia compared with morphine but caused fewer adverse events in a phase IIB study (Singla et al., 2017). However, presently available clinical data rely on short-term administration, i.e., are unsuitable to determine whether the reduced desensitization, constipation, and respiratory depression also occur with chronic treatment. In a different approach, other investigators have used the crystal structure of $\mu$ opioid receptors and docking studies with over three million molecules to identify another ligand with strong bias for the $\mathrm{G}$ protein compared with arrestin pathways (Manglik et al., 2016); however, the leading ligand identified in this study has not yet been tested clinically. Biased agonists have also been described for $\kappa$ opioid receptors (White et al., 2014), but the relevance for this subtype in analgesia remains unclear.

\section{The Unfulfilled Promise of Biased Agonism}

AT1Rs are modulators of many cardiovascular and renal functions; antagonists at these receptors have beneficial effects in corresponding disease and are clinically established drugs (Michel et al., 2016) but the clinically used AT1R antagonists do not exhibit biased agonism (Michel et al., 2013). However, experimental AT1R antagonists (Szakadáti et al., 2015) and analogs of the endogenous agonist angiotensin II (Domazet et al., 2015) exhibit biased agonism. Therefore, investigators at Trevena also developed biased agonists at AT1R. They reasoned that the optimal ligand should be a potent antagonist for $G$ protein activation via AT1R but a biased agonist promoting arrestin recruitment. Based on these considerations, they have identified $N$-methylglycyl-Larginyl-L-valyl-L-tyrosyl-L-isoleucyl-L-histidyl-L-prolyl-Dalanine (TRV 027) (formerly known as TRV 120027). It was found that TRV 027 inhibited angiotensin-stimulated G protein signaling and stimulated arrestin recruitment and activated several kinase pathways, including ERK, src, and endothelial nitric oxide synthase phosphorylation (Violin et al., 2010). Similar to clinically used AT1R antagonists, TRV 027 reduced blood pressure, but unlike the unbiased antagonists it increased cardiac performance. This compound showed promising results in a dog model of congestive heart failure (Boerrigter et al., 2012). However, a clinical phase II study (i.e., the BLAST-AHF study; see Pang et al., 2017) failed to meet its composite primary endpoint consisting of the following: 1) time from baseline to death through day $30 ; 2$ ) time from baseline to heart failure rehospitalization through day $30 ; 3$ ) the first assessment time point following worsening heart failure through day 5 ; 4) change in the dyspnea visual analog scale score calculated as the area under the curve representing the change from baseline over time from baseline through day 5; and 5) length of initial hospital stay (in days) from baseline (Pang et al., 2017).

Many reasons may potentially explain why a novel drug fails to reach its primary endpoint in a clinical proof-of-concept study. However, it is noteworthy that the clinically most advanced drug candidate based on biased agonism is an agonist at $\mu$ opioid receptors. This is a mechanism of action that has been known for more than a century and numerous clinical and preclinical investigations have elaborated on the properties of morphine and how it decreases pain, causes tolerance, and induces constipation and respiratory depression. Thus, the analgesic properties of opioid receptor agonists may be one of the best understood mechanisms in all of pharmacology. This is not likely to be the case for drug candidates that are based on novel targets.

\section{The Challenge for Drug Discovery}

Two technical obstacles exist for leveraging the promise of biased agonism for drug discovery. First, quantification of bias is not a trivial thing. Several useful approaches have been developed (Kenakin, 2015b; Luttrell et al., 2015; Stott et al., 2016; Gundry et al., 2017; Onaran et al., 2017), with $\Delta \Delta \log (\tau /$ $\left.K_{\mathrm{A}}\right)$ or $\Delta \Delta \log \left(E_{\max } / \mathrm{EC}_{50}\right)$ being perhaps the most useful tools currently available (Winpenny et al., 2016). However, it has recently been demonstrated that the kinetic context at the level of ligand-receptor and receptor-pathway kinetics is also a key consideration, which further complicates the interpretation of data (Klein Herenbrink et al., 2016; Lane et al., 2017). Identification of suitable screening assays for biased agonism, particularly high-throughput assays, is not trivial either, but there is theory to address this (Luttrell et al., 2015) and examples of practical implementation (Winpenny et al., 2016; McAnally et al., 2017). For reasons of scope, these obstacles will not be discussed further here.

In our view, the biggest challenge for drug discovery based on biased agonism is establishing the correct target product profile (TPP), which is used to determine how effective the ligand to be developed should be for each signaling pathway. We illustrate this challenge largely based on the example of drug discovery for $\beta_{3}$-adrenoceptor agonists, a novel drug class for the treatment of the overactive bladder (OAB) syndrome (Ohlstein et al., 2012; Chapple et al., 2014).

The signaling response to a receptor ligand depends on a combination of factors attributable to the ligand and the cell type/tissue in which it acts (ligand and system bias, respectively) (Kenakin, 2015a), and any changes this system may undergo in a pathologic setting (dynamic bias) (Michel et al., 2014). Thus, the TPP of the lead compound for development must make assumptions about which cell type harbors the molecular target responsible for desired and potential adverse effects, which signaling pathways mediate such effects, and how this may be modulated in disease. Most $\beta_{3}$-adrenoceptor agonists that have entered clinical development originally had been selected for the treatment of type 2 diabetes and obesity at a time when little knowledge was available about biased agonism and its implications; development for OAB syndrome was a repurposing endeavor (Michel and Korstanje, 2016). When repurposing studies for the $\mathrm{OAB}$ syndrome indication began, it had been assumed that the cellular target is the smooth muscle cell in the urinary bladder detrusor and that it mediates its desirable effects by increasing intracellular cAMP concentrations. Therefore, primary and secondary screens for suitable compounds in various companies were based on cAMP generation and relaxation of isolated detrusor strips in an organ bath, respectively, for instance, for mirabegron (Takasu et al., 2007), ritobegron (Maruyama et al., 2012), solabegron (Hicks et al., 2007), and vibegron (Moyes et al., 2014). While one of these compounds has successfully 
undergone clinical development (Chapple et al., 2014) this may have been pure luck. Thus, while such drugs were already in clinical development, it became clear that cAMP generation plays a minor role (if any role at all) in mediating detrusor smooth muscle relaxation by $\beta$-adrenoceptor agonists (Frazier et al., 2005; Uchida et al., 2005). Perhaps even more importantly, it is now increasingly being questioned whether the detrusor smooth muscle cell is indeed the cellular target of this drug class or rather is indirectly modulated via the urothelium, afferent nerves, or other structures (Michel, 2015). Therefore, even with today's knowledge it is difficult to say which cell type (system bias) and which signaling pathway (ligand bias) would be the optimal target for the treatment of $\mathrm{OAB}$ syndrome.

Moreover, $\beta_{3}$-adrenoceptor ligands for the treatment of $\mathrm{OAB}$ syndrome must be agonists, and based on their mode of action are assumed to provide symptom relief but not cure, indicating that long-term treatment may be required. Desensitization is a general issue with extended treatment with GPCR agonists, and biased agonism may affect speed and extent of desensitization (Raehal et al., 2011), including those of $\beta$-adrenoceptors (Gimenez et al., 2015). Therefore, it would be interesting to know whether the $\beta_{3}$-adrenoceptor agonists used or intended for use in $\mathrm{OAB}$ syndrome treatment differ with regard to biased agonism and how this affects their susceptibility for desensitization. Whether any of the clinically tested $\beta_{3}$-adrenoceptor agonists is a biased agonist remains unknown, but multiple experimental $\beta_{3}$-adrenoceptor ligands are biased agonists (Evans et al., 2010). However, recent data show that both cAMP formation and ERK phosphorylation can undergo agonist-induced desensitization when expressed in Chinese hamster ovary cells, but that the pattern of desensitization differs between the two signaling pathways (Okeke et al., 2018).

The aforementioned may be a rather theoretical example since effective drugs have emerged. However, it illustrates how lack of pathophysiological knowledge increases risk in defining a TPP. If neither the cell type nor the signaling pathway leading to desired therapeutic effect is known with certainty, it remains a high-stakes gamble to define the desirable molecular properties of a drug development candidate, i.e., whether it should be a biased agonist, and if so for which signaling pathway. Only early translational approaches (most likely based on animal models) will be able to test whether a TPP based on biased agonism is viable. Strategies for translational pathway validation have been reported (Rominger et al., 2014) but do not address the validity of the inherent assumptions about validity of the model being used for the human target tissue and its alterations in disease.

Animal models still play a key role in target validation activities for many disease states, particularly through the widespread use of knockout mouse models. It is not common, however, for the degree of agonist bias to be studied at different species orthologs of the human receptor. The often tacit assumption that the pathway bias of a particular compound is maintained in other species presents another potential risk when ascribing the required degree of bias for a particular disease. This can be exemplified by studies on the histamine $\mathrm{H}_{4}$ receptor. 1-[(5-Chloro- $1 H$-indol-2-yl)carbonyl]4-methylpiperazine (JNJ7777120) was the first selective histamine $\mathrm{H}_{4}$ antagonist described and has been critical in defining a role for the $\mathrm{H}_{4}$ receptor in a variety of allergic and inflammatory processes (Thurmond et al., 2008). In 2011, however, it was discovered that although JNJ7777120 was an antagonist/inverse agonist at the human $\mathrm{H}_{4}$ receptor-mediated $\mathrm{G}_{\alpha \mathrm{i}}$ pathway, it was a partial agonist for the recruitment of $\beta$-arrestin to the human $\mathrm{H}_{4}$ receptor (Rosethorne and Charlton, 2011). Furthermore, it was able to induce prolonged ERK activation. While this unexpected biased agonism at the human receptor clearly complicates the interpretation of previous studies that assumed pure antagonism, the waters were muddied further when the activity of JNJ7777120 was tested in a number of species orthologs of the $\mathrm{H}_{4}$ receptor. Surprisingly, and in stark contrast to the human receptor, JNJ7777120 was a partial agonist at the $\mathrm{G}_{\alpha \mathrm{i}}$ pathway from the mouse, rat, and $\operatorname{dog} \mathrm{H}_{4}$ receptor (Schnell et al., 2011). This suggests that the beneficial effects of JNJ7777120 in the mouse (Thurmond et al., 2004) may be via $\mathrm{H}_{4}$-mediated $\mathrm{G}_{\alpha \mathrm{i}}$ activation, rather than inhibition, potentially leading to the wrong choice of pathway for treating human disease. These species differences also raise concerns over interpretation of safety studies that often use the rat and dog as preferred species for the evaluation of toxicology. Thus, biased agonism simply being a probe-dependent form of allostery and allosteric effects being species dependent, it should not be surprising that biased agonism observed in one species does not necessarily translate to others.

System bias (i.e., the stochiometric ratios between relevant signaling molecules) and dynamic bias (i.e., their possible alterations in disease and/or with treatment) are key in establishing the optimal TPP. As indicated previously, the signaling pathway being activated by a ligand depends on its intrinsic properties (ligand bias) and those of the cell type that is targeted (system bias). A key element that influences system bias is the stochiometric ratio of the different signaling molecules that are able to bind to activated receptor conformations (Onfroy et al., 2017), which is likely to differ considerably between cell types and tissues. To highlight this point, we have analyzed data on mRNA expression of several thousand genes across a panel of 31 human tissues (Uhlén et al., 2015). This analysis shows that the ratio between expression of $\mathrm{G}_{\mathrm{s}}, \mathrm{G}_{\mathrm{i}}$, and arrestin is highly variable between tissues (Fig. 1). While these data are based on mRNA expression and we do not know how this translates into functional protein in those tissues, it is safe to assume that a similar lack of correlation will hold true at the protein level and also when cell types rather than tissues are analyzed. Moreover, if differential expression of these three elements exists across human tissues, it is likely that similar differential expression exists in animal models compared with patients.

To further complicate matters, expression of these various signaling components within a given cell type of tissue can be modulated by disease. For instance, congestive heart failure (the condition in which TRV 027 did not meet its primary endpoint) is characterized by desensitization and downregulation of $\beta_{1}$-adrenoceptors (with less, if any, desensitization and downregulation of $\beta_{2}$-adrenoceptors), downregulation of $\mathrm{G}_{\mathrm{s}}$, and upregulation of $\mathrm{G}_{\mathrm{i}}, \beta$-arrestin- 1 , and $\mathrm{G}$ protein-coupled receptor kinases (Brodde, 2007). Thus, a signaling pathway that may have been important in healthy tissue may be less or more prominent in disease tissue. We have proposed to call such alterations of the signalosome dynamic bias (Michel et al., 2014). 


\section{GNAS vs GNAI2}

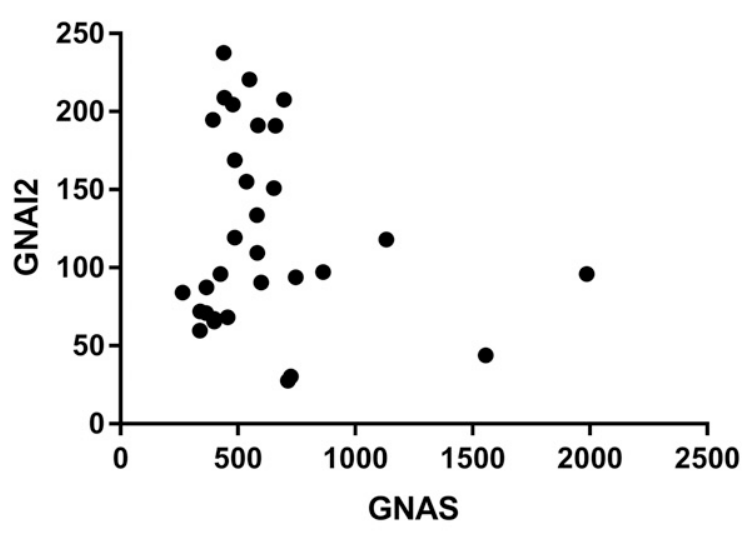

GNAS vs ARRB2

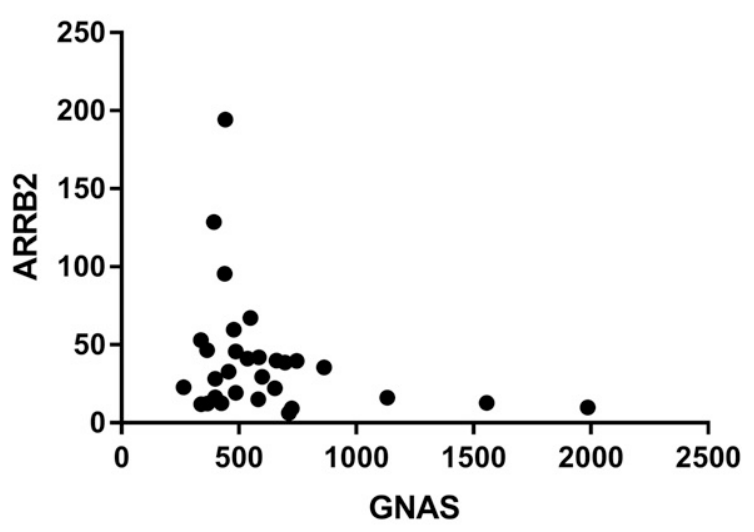

GNAI2 vS ARRB2

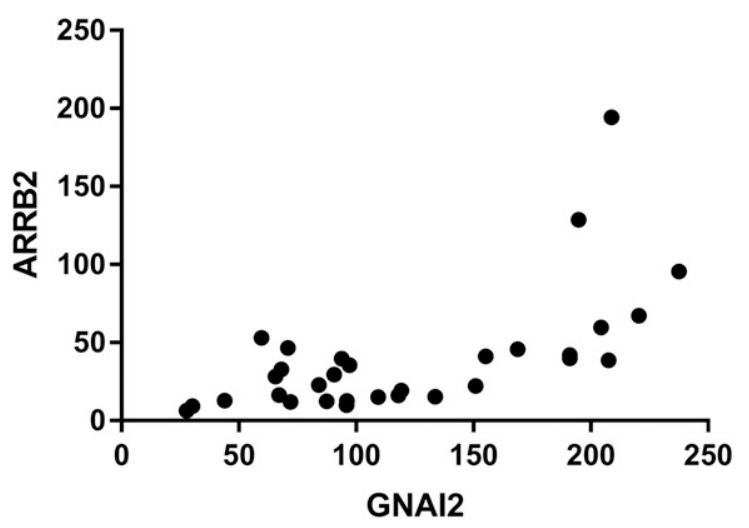

Fig. 1. Comparison of relative mRNA expression in a panel of 31 human tissues for $\mathrm{G}_{\mathrm{s}}$ (GNAS), $\mathrm{G}_{\mathrm{i} 2}$ (GNAI2), and $\beta$-arrestin (ARRB2). All data are expressed in fragments per kilobase million and the mean values of two to seven individual subjects. The data are based on Uhlén et al. (2015).

\section{Conclusions}

While it is clear that correctly assigning the required bias for a new receptor is currently very difficult, there are several technological advances that promise to shed more light on the discrete signaling pathways activated in disease. In particular, novel imaging approaches to dissect individual pathways in living cells, tissues, and animals will allow better matching of the kinetics and signal strength to a particular phenotypic response. Förster resonance energy transfer-based imaging biosensors have been developed that can monitor the spatiotemporal characteristics of signaling pathways (e.g., calcium, cAMP, and phosphorylated ERK) in single cells and even subcellular compartments (Lohse et al., 2012; Halls et al., 2015). More exciting still is the recent use of genetically encoded versions of these sensors to measure spatiotemporal signaling at the whole organ level in living animals (van Unen et al., 2015; Jones-Tabah et al., 2017). Using a microendoscopic implant, signaling via protein kinase $\mathrm{A}$ and $\mathrm{ERK}_{1 / 2}$ has been imaged in the striatum of mice undergoing behavioral testing (Goto et al., 2015; Yamaguchi et al., 2015), representing a step change in our ability to monitor therapeutically relevant signaling pathways in their physiologic context.

The concomitant coupling of a single receptor to multiple signaling pathways and the selectivity for one of them that can theoretically be achieved by biased agonists is an attractive concept for drug discovery. However, definition of a sound TPP requires a lot of assumptions on system bias and dynamic bias, most importantly the cell type mediating the desired response and adverse responses, the signaling pathway causing them, and how they behave quantitatively in the disease to be treated. Since such knowledge typically is not available for highly innovative targets at the time lead identification and optimization takes place, we feel that targeted development of biased agonists will be limited to a rather small number of conditions, and even then only in the discovery of second or third generation medicines.

\section{Acknowledgments}

The authors thank Deutsche Forschungsgemeinschaft (Mi 294/8-1) and Velicept Therapeutics for the financial support given for work in the authors' laboratories.

\section{Authorship Contributions}

Participated in research design: Michel, Charlton.

Performed data analysis: Michel, Charlton.

Wrote or contributed to the writing of the manuscript: Michel, Charlton.

\section{References}

Boerrigter G, Soergel DG, Violin JD, Lark MW, and Burnett JC, Jr (2012) TRV120027, a novel $\beta$-arrestin biased ligand at the angiotensin II type I receptor, unloads the heart and maintains renal function when added to furosemide in experimental heart failure. Circ Heart Fail 5:627-634.

Brodde OE (2007) $\beta$-Adrenoceptor blocker treatment and the cardiac $\beta$-adrenoceptorG-protein(s)-adenylyl cyclase system in chronic heart failure. Naunyn Schmiedebergs Arch Pharmacol 374:361-372.

Bylund DB, Eikenberg DC, Hieble JP, Langer SZ, Lefkowitz RJ, Minneman KP, Molinoff PB, Ruffolo RR, Jr, and Trendelenburg U (1994) International Union of Pharmacology nomenclature of adrenoceptors. Pharmacol Rev 46:121-136.

Cao W, Luttrell LM, Medvedev AV, Pierce KL, Daniel KW, Dixon TM, Lefkowitz RJ, and Collins S (2000) Direct binding of activated c-Src to the $\beta_{3}$-adrenergic receptor is required for MAP kinase activation. J Biol Chem 275:38131-38134.

Caulfield MP and Birdsall NJM (1998) International Union of Pharmacology. XVII. Classification of muscarinic acetylcholine receptors. Pharmacol Rev 50:279-290.

Chapple CR, Cardozo L, Nitti VW, Siddiqui E, and Michel MC (2014) Mirabegron in overactive bladder: a review of efficacy, safety, and tolerability. Neurourol Urodyn 33:17-30.

Costa-Neto CM, Parreiras-E-Silva LT, and Bouvier M (2016) A pluridimensional view of biased agonism. Mol Pharmacol 90:587-595.

Crawford KW, Frey EA, and Cote TE (1992) Angiotensin II receptor recognized by DuP753 regulates two distinct guanine nucleotide-binding protein signaling pathways. Mol Pharmacol 41:154-162.

de Gasparo M, Catt KJ, Inagami T, Wright JW, and Unger T (2000) International Union of Pharmacology. XXIII. The angiotensin II receptors. Pharmacol Rev 52: 415-472.

Delgado-Peraza F, Ahn KH, Nogueras-Ortiz C, Mungrue IN, Mackie K, Kendall DA, and Yudowski GA (2016) Mechanisms of biased $\beta$-arrestin-mediated signaling downstream from the cannabinoid 1 receptor. Mol Pharmacol 89:618-629. 
DeWire SM, Yamashita DS, Rominger DH, Liu G, Cowan CL, Graczyk TM, Chen XT, Pitis PM, Gotchev D, Yuan C, et al. (2013) A G protein-biased ligand at the $\mu$-opioid receptor is potently analgesic with reduced gastrointestinal and respiratory dysfunction compared with morphine. J Pharmacol Exp Ther 344:708-717.

Dhawan BN, Cesselin F, Raghubir R, Reisine T, Bradley PB, Portoghese PS, and Hamon M (1996) International Union of Pharmacology. XII. Classification of opioid receptors. Pharmacol Rev 48:567-592.

Domazet I, Holleran BJ, Richard A, Vandenberghe C, Lavigne P, Escher E, Leduc R, and Guillemette G (2015) Characterization of angiotensin II molecular determinants involved in $\mathrm{AT}_{1}$ receptor functional selectivity. Mol Pharmacol 87:982-995.

Evans BA, Sato M, Sarwar M, Hutchinson DS, and Summers RJ (2010) Liganddirected signalling at $\beta$-adrenoceptors. Br J Pharmacol 159:1022-1038.

Frazier EP, Mathy MJ, Peters SLM, and Michel MC (2005) Does cyclic AMP mediate rat urinary bladder relaxation by isoproterenol? J Pharmacol Exp Ther 313 260-267.

Gerhardt CC, Gros J, Strosberg AD, and Issad T (1999) Stimulation of the extracellular signal-regulated kinase 1/2 pathway by human beta-3 adrenergic receptor: new pharmacological profile and mechanism of activation. Mol Pharmacol 55 255-262.

Gimenez LE, Baameur F, Vayttaden SJ, and Clark RB (2015) Salmeterol efficacy and bias in the activation and kinase-mediated desensitization of $\beta_{2}$-adrenergic receptors. Mol Pharmacol 87:954-964.

Goto A, Nakahara I, Yamaguchi T, Kamioka Y, Sumiyama K, Matsuda M, Nakanishi S, and Funabiki K (2015) Circuit-dependent striatal PKA and ERK signaling underlies rapid behavioral shift in mating reaction of male mice. Proc Natl Acad Sci USA 112:6718-6723.

Gundry J, Glenn R, Alagesan P, and Rajagopal S (2017) A practical guide to approaching biased agonism at G protein coupled receptors. Front Neurosci 11:17.

Halls ML, Poole DP, Ellisdon AM, Nowell CJ, and Canals M (2015) Detection and quantification of intracellular signaling using FRET-based biosensors and high content imaging, in G Protein-Coupled Receptors in Drug Discovery: Methods and Protocols (Filizola M ed) pp 131-161, Springer, New York.

Hicks A, McCafferty GP, Riedel E, Aiyar N, Pullen M, Evans C, Luce TD, Coatney RW, Rivera GC, Westfall TD, et al. (2007) GW427353 (solabegron), a novel, selective $\beta_{3}$-adrenergic receptor agonist, evokes bladder relaxation and increases micturition reflex threshold in the dog. J Pharmacol Exp Ther 323:202-209.

Horie K, Itoh H, and Tsujimoto G (1995) Hamster alpha ${ }_{1 \mathrm{~B}}$-adrenergic receptor directly activates $\mathrm{G}_{\mathrm{s}}$ in the transfected Chinese hamster ovary cells. Mol Pharmacol 48:392-400.

Jarpe MB, Knall C, Mitchell FM, Buhl AM, Duzic E, and Johnson GL (1998) [D-Arg ${ }^{1}$, D-Phe ${ }^{5}, \mathrm{D}-\mathrm{Trp}^{7,9}{ }^{\text {,Leu }}{ }^{11}$ ]Substance $\mathrm{P}$ acts as a biased agonist toward neuropeptide and chemokine receptors. J Biol Chem 273:3097-3104.

Jones-Tabah J, Clarke PBS, and Hébert TE (2017) Measuring G protein-coupled receptor signalling in the brain with resonance energy transfer based biosensors. Curr Opin Pharmacol 32:44-48.

Kelly E (2013) Efficacy and ligand bias at the $\mu$-opioid receptor. Br J Pharmacol 169: $1430-1446$.

Kenakin T (1995) Agonist-receptor efficacy. II. Agonist trafficking of receptor signals. Trends Pharmacol Sci 16:232-238.

Kenakin T (2015a) Gaddum Memorial Lecture 2014: receptors as an evolving concept: from switches to biased microprocessors. $\mathrm{Br}$ J Pharmacol 172:4238-4253.

Kenakin T (2015b) The effective application of biased signaling to new drug discovery. Mol Pharmacol 88:1055-1061.

Kenakin T and Christopoulos A (2013) Signalling bias in new drug discovery: detection, quantification and therapeutic impact. Nat Rev Drug Discov 12:205-216.

Kenakin T and Miller LJ (2010) Seven transmembrane receptors as shapeshifting proteins: the impact of allosteric modulation and functional selectivity on new drug discovery. Pharmacol Rev 62:265-304.

Kenakin TP and Morgan PH (1989) Theoretical effects of single and multiple transducer receptor coupling proteins on estimates of the relative potency of agonists. Mol Pharmacol 35:214-222.

Klein Herenbrink C, Sykes DA, Donthamsetti P, Canals M, Coudrat T, Shonberg J, Scammells PJ, Capuano B, Sexton PM, Charlton SJ, et al. (2016) The role of kinetic context in apparent biased agonism at GPCRs. Nat Commun 7:10842.

Kudlacek O, Waldhoer M, Kassack MU, Nickel P, Salmi JI, Freissmuth M, and Nanoff $\mathrm{C}$ (2002) Biased inhibition by a suramin analogue of $\mathrm{A}_{1}$-adenosine receptor/G protein coupling in fused receptor/G protein tandems: the $\mathrm{A}_{1}$-adenosine receptor is predominantly coupled to $\mathrm{Go}_{\alpha}$ in human brain. Naunyn Schmiedebergs Arch Pharmacol 365:8-16.

Lane JR, May LT, Parton RG, Sexton PM, and Christopoulos A (2017) A kinetic view of GPCR allostery and biased agonism. Nat Chem Biol 13:929-937.

Lefkowitz RJ, Pierce KL, and Luttrell LM (2002) Dancing with different partners: protein kinase a phosphorylation of seven membrane-spanning receptors regulates their G protein-coupling specificity. Mol Pharmacol 62:971-974.

Lohse MJ, Nuber S, and Hoffmann C (2012) Fluorescence/bioluminescence resonance energy transfer techniques to study G-protein-coupled receptor activation and signaling. Pharmacol Rev 64:299-336.

Luttrell LM, Maudsley S, and Bohn LM (2015) Fulfilling the promise of "biased" G protein-coupled receptor agonism. Mol Pharmacol 88:579-588.

Manglik A, Kim TH, Masureel M, Altenbach C, Yang Z, Hilger D, Lerch MT, Kobilka TS, Thian FS, Hubbell WL, et al. (2015) Structural insights into the dynamic process of $\beta_{2}$-adrenergic receptor signaling [published correction appears in Cell (2015) 162:1431]. Cell 161:1101-1111.

Manglik A, Lin H, Aryal DK, McCorvy JD, Dengler D, Corder G, Levit A, Kling RC, Bernat V, Hübner H, et al. (2016) Structure-based discovery of opioid analgesics with reduced side effects. Nature 537:185-190.

Manning DR (2002) Measures of efficacy using G proteins as endpoints: differential engagement of $\mathrm{G}$ proteins through single receptors. Mol Pharmacol 62:451-452.

Maruyama I, Tatemichi S, Goi Y, Maruyama K, Hoyano Y, Yamazaki Y, and Kusama $\mathrm{H}$ (2012) Effects of ritobegron (KUC-7483), a novel selective $\beta_{3}$-adrenoceptor agonist, on bladder function in cynomolgus monkey. J Pharmacol Exp Ther 342 : $163-168$.

Maudsley S, Martin B, Gesty-Palmer D, Cheung H, Johnson C, Patel S, Becker KG, Wood WH, III, Zhang Y, Lehrmann E, et al. (2015) Delineation of a conserved arrestin-biased signaling repertoire in vivo. Mol Pharmacol 87:706-717.

McAnally D, Siddiquee K, Sharir H, Qi F, Phatak S, Li JL, Berg E, Fishman J, and Smith L (2017) A systematic approach to identify biased agonists of the apelin receptor through high-throughput screening. SLAS Discov 22:867-878.

Michel MC (2015) Therapeutic modulation of urinary bladder function: multiple targets at multiple levels. Annu Rev Pharmacol Toxicol 55:269-287.

Michel MC and Alewijnse AE (2007) Ligand-directed signaling: 50 ways to find a lover. Mol Pharmacol 72:1097-1099.

Michel MC, Brunner HR, Foster C, and Huo Y (2016) Angiotensin II type 1 receptor antagonists in animal models of vascular, cardiac, metabolic and renal disease. Pharmacol Ther 164:1-81.

Michel MC, Foster C, Brunner HR, and Liu L (2013) A systematic comparison of the properties of clinically used angiotensin II type 1 receptor antagonists. Pharmacol Rev 65:809-848.

Michel MC and Korstanje C (2016) $\beta_{3}$-Adrenoceptor agonists for overactive bladder syndrome: role of translational pharmacology in a repositioning clinical drug development project. Pharmacol Ther 159:66-82.

Michel MC, Seifert R, and Bond RA (2014) Dynamic bias and its implications for GPCR drug discovery. Nat Rev Drug Discov 13:869-870.

Moyes CR, Berger R, Goble SD, Harper B, Shen DM, Wang L, Bansal A, Brown PN, Chen AS, Dingley KH, et al. (2014) Design, synthesis, and evaluation of conformationally restricted acetanilides as potent and selective $\beta_{3}$ adrenergic receptor agonists for the treatment of overactive bladder. J Med Chem 57:1437-1453.

Ohlstein EH, von Keitz A, and Michel MC (2012) A multicenter, double-blind, randomized, placebo-controlled trial of the $\beta_{3}$-adrenoceptor agonist solabegron for overactive bladder. Eur Urol 62:834-840.

Okeke K, Michel-Reher M, and Michel MC (2018) $\beta 3$-Adrenoceptor desensitisation in CHO cells: comparison of cAMP and ERK signalling. pA2 online in press.

Onaran HO, Ambrosio C, Uğur Ö, Madaras Koncz E, Grò MC, Vezzi V, Rajagopal S, and Costa T (2017) Systematic errors in detecting biased agonism: analysis of current methods and development of a new model-free approach. Sci Rep 7:44247.

Onfroy L, Galandrin S, Pontier SM, Seguelas MH, N'Guyen D, Sénard JM, and Galés $\mathrm{C}$ (2017) G protein stoichiometry dictates biased agonism through distinct receptor-G protein partitioning. Sci Rep 7:7885.

Pang PS, Butler J, Collins SP, Cotter G, Davison BA, Ezekowitz JA, Filippatos G, Levy PD, Metra M, Ponikowski P, et al. (2017) Biased ligand of the angiotensin II type 1 receptor in patients with acute heart failure: a randomized, double-blind, placebocontrolled, phase IIB, dose ranging trial (BLAST-AHF). Eur Heart $J$ 38:2364-2373.

Patel CB, Noor N, and Rockman HA (2010) Functional selectivity in adrenergic and angiotensin signaling systems. Mol Pharmacol 78:983-992.

Peterson YK and Luttrell LM (2017) The diverse roles of arrestin scaffolds in G protein-coupled receptor signaling. Pharmacol Rev 69:256-297.

Raehal KM, Schmid CL, Groer CE, and Bohn LM (2011) Functional selectivity at the $\mu$-opioid receptor: implications for understanding opioid analgesia and tolerance. Pharmacol Rev 63:1001-1019.

Rominger DH, Cowan CL, Gowen-MacDonald W, and Violin JD (2014) Biased ligands: pathway validation for novel GPCR therapeutics. Curr Opin Pharmacol 16: 108-115.

Rosethorne EM and Charlton SJ (2011) Agonist-biased signaling at the histamine $\mathrm{H}_{4}$ receptor: JNJ7777120 recruits $\beta$-arrestin without activating $\mathrm{G}$ proteins. $\mathrm{Mol}$ Pharmacol 79:749-757.

Sato M, Hutchinson DS, Evans BA, and Summers RJ (2008) The $\beta_{3}$-adrenoceptor agonist 4-[[(hexylamino)carbonyl] amino]- $N$-[4-[2-[[(2S)-2-hydroxy-3-(4-hydroxyphenoxy)propyl]amino]ethyl]-phenyl]-benzenesulfonamide (L755507) and antagonist $(S)-N$-[4-[2-[[3-[3-(acetamidomethyl)phenoxy]-2-hydroxypropyl]amino]-ethyl] phenyl]benzenesulfonamide (L748337) activate different signaling pathways in Chinese hamster ovary-K1 cells stably expressing the human $\beta_{3}$-adrenoceptor. $\mathrm{Mol}$ Pharmacol 74:1417-1428.

Schmidt M, Bienek C, van Koppen CJ, Michel MC, and Jakobs KH (1995) Differential calcium signalling by $\mathrm{m} 2$ and $\mathrm{m} 3$ muscarinic acetylcholine receptors in a single cell type. Naunyn Schmiedebergs Arch Pharmacol 352:469-476.

Schnell D, Brunskole I, Ladova K, Schneider EH, Igel P, Dove S, Buschauer A, and Seifert R (2011) Expression and functional properties of canine, rat, and murine histamine $\mathrm{H}_{4}$ receptors in Sf9 insect cells. Naunyn Schmiedebergs Arch Pharmacol 383:457-470.

Seifert R and Dove S (2009) Functional selectivity of GPCR ligand stereoisomers: new pharmacological opportunities. Mol Pharmacol 75:13-18.

Singla N, Minkowitz HS, Soergel DG, Burt DA, Subach RA, Salamea MY, Fossler MJ, and Skobieranda F (2017) A randomized, phase IIb study investigating oliceridine (TRV130), a novel $\mu$-receptor G-protein pathway selective ( $\mu$-GPS) modulator, for the management of moderate to severe acute pain following abdominoplasty. J Pain Res 10:2413-2424

Soeder KJ, Snedden SK, Cao W, Della Rocca GJ, Daniel KW, Luttrell LM, and Collins $\mathrm{S}$ (1999) The $\beta_{3}$-adrenergic receptor activates mitogen-activated protein kinase in adipocytes through a $\mathrm{G}_{\mathrm{i}}$-dependent mechanism. $J$ Biol Chem 274 12017-12022.

Staus DP, Strachan RT, Manglik A, Pani B, Kahsai AW, Kim TH, Wingler LM, Ahn S, Chatterjee A, Masoudi A, et al. (2016) Allosteric nanobodies reveal the dynamic range and diverse mechanisms of G-protein-coupled receptor activation. Nature 535:448-452.

Stott LA, Hall DA, and Holliday ND (2016) Unravelling intrinsic efficacy and ligand bias at $\mathrm{G}$ protein coupled receptors: a practical guide to assessing functional data. Biochem Pharmacol 101:1-12.

Szakadáti G, Tóth AD, Oláh I, Erdélyi LS, Balla T, Várnai P, Hunyady L, and Balla A (2015) Investigation of the fate of type I angiotensin receptor after biased activation. Mol Pharmacol 87:972-981. 
Takasu T, Ukai M, Sato S, Matsui T, Nagase I, Maryama T, Sasamata M, Miyata K, Uchida H, and Yamaguchi O (2007) Effect of $(R)-2$-(2-aminothiazol-4-yl)-4' -\{2-[(2hydroxy-2-phenylethyl)amino]ethyl\} acetanilide (YM178), a novel selective $\beta_{3^{-}}$ adrenoceptor agonist, on bladder function. J Pharmacol Exp Ther 321:642-647.

Thurmond RL, Desai PJ, Dunford PJ, Fung-Leung WP, Hofstra CL, Jiang W, Nguyen S, Riley JP, Sun S, Williams KN, et al. (2004) A potent and selective histamine $\mathrm{H}_{4}$ receptor antagonist with anti-inflammatory properties. J Pharmacol Exp Ther 309:404-413.

Thurmond RL, Gelfand EW, and Dunford PJ (2008) The role of histamine $\mathrm{H}_{1}$ and $\mathrm{H}_{4}$ receptors in allergic inflammation: the search for new antihistamines. Nat Rev Drug Discov 7:41-53.

Uchida H, Shishido K, Nomiya M, and Yamaguchi O (2005) Involvement of cyclic AMP-dependent and -independent mechanisms in the relaxation of rat detrusor muscle via $\beta$-adrenoceptors. Eur J Pharmacol 518:195-202.

Uhlén M, Fagerberg L, Hallström BM, Lindskog C, Oksvold P, Mardinoglu A, Sivertsson A, Kampf C, Sjöstedt E, Asplund A, et al. (2015) Proteomics. Tissuebased map of the human proteome. Science 347:1260419.

van Unen J, Woolard J, Rinken A, Hoffmann C, Hill SJ, Goedhart J, Bruchas MR, Bouvier M, and Adjobo-Hermans MJW (2015) A perspective on studying G-protein-coupled receptor signaling with resonance energy transfer biosensors in living organisms. Mol Pharmacol 88:589-595.

Violin JD, DeWire SM, Yamashita D, Rominger DH, Nguyen L, Schiller K, Whalen EJ, Gowen M, and Lark MW (2010) Selectively engaging $\beta$-arrestins at the angiotensin II type 1 receptor reduces blood pressure and increases cardiac performance. J Pharmacol Exp Ther 335:572-579.

Viscusi ER, Webster L, Kuss M, Daniels S, Bolognese JA, Zuckerman S, Soergel DG, Subach RA, Cook E, and Skobieranda F (2016) A randomized, phase 2 study investigating TRV130, a biased ligand of the $\mu$-opioid receptor, for the intravenous treatment of acute pain. Pain 157:264-272.

Wenzel-Seifert K and Seifert R (2000) Molecular analysis of $\beta_{2}$-adrenoceptor coupling to $\mathrm{G}_{\mathrm{s}^{-}}, \mathrm{G}_{\mathrm{i}^{-}}$, and $\mathrm{G}_{\mathrm{q}}$-proteins. Mol Pharmacol 58:954-966.

Whistler JL, Chuang H, Chu P, Jan LY, and von Zastrow M (1999) Functional dissociation of $\mu$ opioid receptor signaling and endocytosis: implications for the biology of opiate tolerance and addiction. Neuron 23:737-746.

White KL, Scopton AP, Rives ML, Bikbulatov RV, Polepally PR, Brown PJ, Kenakin T, Javitch JA, Zjawiony JK, and Roth BL (2014) Identification of novel functionally selective $\kappa$-opioid receptor scaffolds. Mol Pharmacol 85:83-90.

Winpenny D, Clark M, and Cawkill D (2016) Biased ligand quantification in drug discovery: from theory to high throughput screening to identify new biased $\mu$ opioid receptor agonists. Br J Pharmacol 173:1393-1403.

Wisler JW, DeWire SM, Whalen EJ, Violin JD, Drake MT, Ahn S, Shenoy SK and Lefkowitz RJ (2007) A unique mechanism of $\beta$-blocker action: carvedilol stimulates $\beta$-arrestin signaling. Proc Natl Acad Sci USA 104:16657-16662.

Yamaguchi T, Goto A, Nakahara I, Yawata S, Hikida T, Matsuda M, Funabiki K, and Nakanishi S (2015) Role of PKA signaling in D2 receptor-expressing neurons in the core of the nucleus accumbens in aversive learning. Proc Natl Acad Sci USA 112:11383-11388.

Address correspondence to: Martin C. Michel, Department of Pharmacology, Johannes Gutenberg University, Obere Zahlbacher Strasse, 67, 55131 Mainz, Germany. E-mail: marmiche@uni-mainz.de 